\title{
Virtual Healthcare: A Literature Review in Business and Management Field
}

\author{
Stefania Mele ${ }^{1} \&$ Filomena Izzo ${ }^{1}$ \\ ${ }^{1}$ University of Campania "Luigi Vanvitelli”, Economics Department, Capua (CE), Italy \\ Correspondence: Filomena Izzo, University of Campania "Luigi Vanvitelli”, Economics Department, Capua \\ (CE), Italy. E-mail: filomena.izzo@unicampania.it
}

Received: February 15, 2021

Accepted: March 16, 2021

Online Published: April 2, 2021

doi:10.5539/ijbm.v16n5p25

URL: https://doi.org/10.5539/ijbm.v16n5p25

\begin{abstract}
Virtual healthcare has evolved through different research and application steps, this study tries to systematize what has happened in this disruptive situation in management studies, consolidating lessons learned in last twenty years. A bibliometric analysis gives the opportunity to explore in a massive method what was written in 2020, including instant papers and preprints, trying to concentrate on new emerging topics and research fields.
\end{abstract}

Keywords: Virtual healthcare, telemedicine, digital healthcare, Covid, Bibliometrix

\section{Introduction}

IC and digital technologies are completely changing the healthcare field (Sousa et. al., 2019; Izzo, Camminatiello, 2020) especially after an incredible change of the scenario due to Covid-19 pandemic emergency (Cobianchi, Pugliese, 2020). Social distancing, together with the difficulty to give cures to an enormous number of patients in fact put on evidence the necessity of telemedicine and digital healthcare.

Digital healthcare in 2020 has been acting an increasingly major position in the management of the COVID-19 crisis and research studies are becoming to indagate the new role of telehealth both in emergency and in new sanitary models defining a new scenario also in study field. This impressing acceleration, due to pandemic evolvement, generates the need to investigate in new digital healthcare solution in new settings and systematize recent experience in a theoretical framework.

This paper has the aim to provide a systematic literature review to systematically analyse the effect of digital healthcare, especially in Covid time. Indeed, we performed an analysis of 168 documents of the last 22 years (from 1998, year in which first telemedicine discussions were implemented also in European institutional context, to 2020) evidencing new and consolidate application of virtual healthcare. The number of documents until 2019, comparing with 2020 ones, reveal a gap of systematization and a need to include new applications in a consolidated research field.

The paper is organised as follows: after illustrating the methodology used, the authors systematically review the literature about the effect of virtual healthcare on health system especially in Covid- 19 time. Afterwards, more illustrations of results driven by literature are presented. In the last section of the chapter, the main conclusions and implications are discussed.

\section{Methodology}

The research contains five phases: study design; data collection; data analysis; data visualization and interpretation.

In the study design, we define the main objective of this research that is to evaluate and classify the different characteristics of existing literature that lies at the crossing among virtual healthcare and sustainable sanitary models, especially in Covid pandemic emergency in management realms. We adopt an objective and a subjective approach to examine how the topic of virtual healthcare and telemedicine has been integrated into the business and management field.

For data collection we select the Web of Science (WoS) database. Data analysis is staged by a bibliometric analysis which characterizes the objective approach. Bibliometrics refers to "the collection, the handling and the analysis of quantitative bibliographic data, derived from scientific publications" (Verbeek et al., 2002: 181). 
In research project, scientists define the study question and decide the appropriate bibliometric methods that can solve the question. The common kinds of research questions that can be answered by means of bibliometrics for science mapping are: classifying the knowledge base of a research field and its intellectual structure; investigate the study front (or conceptual structure) of a research field; generating a social network structure of a specific scientific community. In research design, one of the most significant choices for researchers is the extent or decision to divide the timespan into time segments. Bibliometric evaluation is performed at a specific observation in time to represent a static portrait of the field at that moment; it can divide the timespan into multiple time periods to catch the development of the field through time. This is particularly useful for this research on technology evolvement and use.

In data set, scholars select the database that includes the bibliometric data, filter the main document set, and transfer the data from the selected database. This phase can include constructing one's own database (Waltman, 2016). For data analysis, one or more bibliometric or statistical software tools can be utilized. Data assessment requires descriptive analysis and network mining. The last stage is records visualization: researchers must decide what visualization technique is to be employed on the results and then engage the appropriate mapping software: bibliometric methods will often disclose the structure of a ground in a different way from the cataloguing of traditional literature reviews. Of course, they are not a substitute for extensive reading in the field but could represents an updated situation in scholars' research. This graphical representation is useful to underlie research gaps: as for specific topics, for authors' network and for country areas involvement. The bibliometric analysis research question is how identify lack of literature engagement in virtual healthcare field.

The study contains general descriptive statistics (e.g. identifying the main authors, publishing journals, etc) (Wu and $\mathrm{Wu}, 2017)$ and more sophisticated methods like the document co-citation, collaboration, and co-occurrence analyses (Briner and Denyer, 2012; Rosseau, 2012). The bibliometric analysis is carried out by using the R package bibliometrix version 2.2.1 (Aria \& Cuccurullo, 2017) which also allows for extracting bibliometric networks using different units of analysis, i.e. citations, authors, countries, keywords, etc. It performs coword analysis (Callon et al., 1983) by multiple correspondence analysis (Lebart et al., 1984) and hierarchical agglomerative clustering (Rousseeuw, 1987). Bibliometrics can make a systematic, transparent, and reproducible review process based on the statistical measurement of science, scientists, or scientific activity (Broadus, 1987; Diodato, 1994; Pritchard, 1969; Crane, 1972). Data visualization is used to represent a science map and the result of data analysis.

The last step is interpretation, where the objective method is combined by a subjective approach (qualitative analysis), which is based on scholars' analysis of a given area of research. In fact, a qualitative evaluation completes the bibliometric analysis, in particular the literature linking virtual healthcare in business and management phenomena is studied and graded.

\section{Results of the Bibliometric Analysis and Discussion}

We conducted a topical query and downloaded 5475 bibliographic literature from the online WoS database searching for Topic TS = ((Covid AND virtual healthcare AND ("Integrated citizen*" OR "global health coverage")) AND (telemedicine OR telehealth) OR e-health)) in 1998-2020, refined:

- by including web of science categories: (Management or Business);

- by including languages: (English);

- $\quad$ by including citations Indexes: SCI-EXPANDED, SSCI, A\&HCI, CPCI-S, CPCI-SSH, ESCI.

We extracted by 121 sources (Table 1.). Then we carried out the bibliometric analysis, by using the R package Bibliometrix version 2.2.1 (Aria \& Cuccurullo, 2017). Such analysis opens by presenting the main information about data (Table 1). 
Table 1. Main Information about data

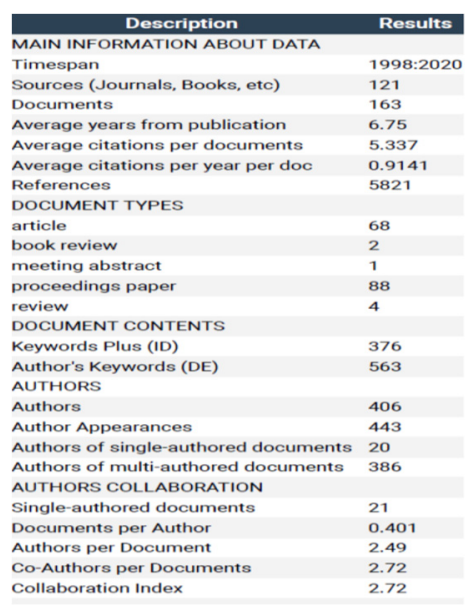

Leaving out the rows whose meaning is obvious, we put on evidence the row that evidences the number of keywords associated with the documents by WoS database (ID=376), then the number of keywords associated with the documents by the authors $(\mathrm{DE}=563)$. The table data also denote a few documents e many authors, the number of Co Authors per documents (2.72) is equal the collaboration index (2.86) that is obtained by dividing the number of authors of multi authored documents and the multi authored documents. This index indicates a strong collaboration among the authors.

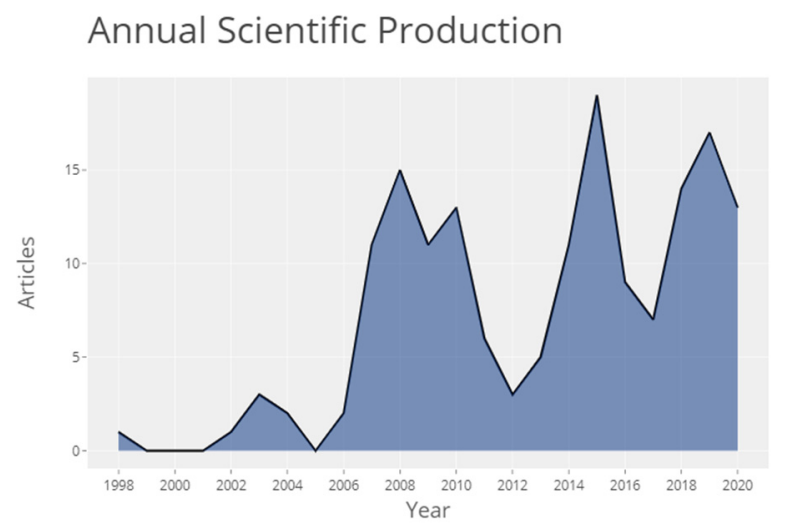

Figure 1. Annual scientific production

As the figure put on evidence starting from 1998, year in which was written the first article dedicated to this argument, the literature production had a strong increase in the middle of 2000's and except for some oscillations has an important trend of production with some peaks in recent years. The scientific production follows the technology improvement: the introduction on new devices impact on healthcare applications, the large-scale diffusion of smartphones and applications between common users represent each time a step in the digital healthcare progress and then in literature creation (Elton and O' Riordan, 2016).

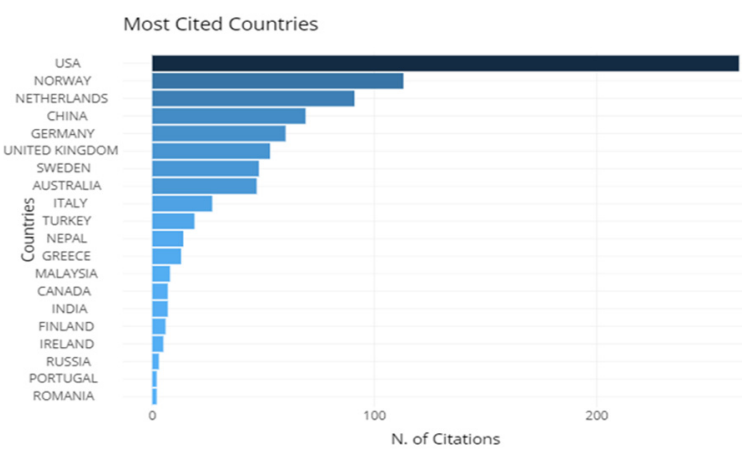

Figure 2. Most cited countries 
Figure 2 shows numbers of citations per countries. This citation analysis explains in which countries are most frequent citation and then the interrelation between documents in each country. The first one is USA, followed by Norway and Netherlands, then most sensible context to these themes. This figure is particularly explained by the Table 2, as follows, in which citations are counted in each country and is indicated average article citations. These three countries have a tradition in virtual healthcare thanks to technology level in sanitary field due also to demographic patterns (Vitacca et al., 2009). The function "citations" generate the frequency table of the most cited references or the most cited first authors (of references).

Table 2. Citations per country

\begin{tabular}{lll}
\multicolumn{1}{c}{ Country } & Total Citations & Average Article Citations \\
\hline USA & 264 & 10.154 \\
NORWAY & 113 & 28.250 \\
NETHERLANDS & 91 & 15.167 \\
CHINA & 69 & 9.857 \\
GERMANY & 60 & 10.000 \\
UNITED KINGDOM & 53 & 5.300 \\
SWEDEN & 48 & 9.600 \\
AUSTRALIA & 47 & 3.917 \\
ITALY & 27 & 6.750 \\
TURKEY & 19 & 9.500 \\
NEPAL & 14 & 14.000 \\
GREECE & 13 & 4.333 \\
MALAYSIA & 8 & 1.143 \\
CANADA & 7 & 1.750 \\
INDIA & 7 & 3.500 \\
FINLAND & 6 & 0.750 \\
IRELAND & 5 & 5.000 \\
RUSSIA & 3 & 1.500 \\
PORTUGAL & 2 & 0.500 \\
ROMANIA & 2 & 0.222 \\
& &
\end{tabular}

For a choice of simplicity, we summarize the main results of the bibliometric analysis in several tables, such as "Most Productive Authors" (Table 3), "Top Manuscripts per Number of Citations" (Table 4), "Most Relevant Sources" (Table 5) and "Most Relevant Keywords" (Table 6).

Table 3 shows the three authors who produced more than one publication and the number of articles they authored or co-authored. All the authors published almost two articles, thus reflecting that researching on virtual healthcare is a recent interest but every author decided to follow this theme after a first publication.

Table 4 illustrates the top twenty manuscripts per citations. These are highly cited papers given that their citations.

Analysing top twenty sources we can see that the topic virtual healthcare/ telemedicine has been published no more than eight times even if we deal with specialized journals, revealing that very not many sources deal with the topic (Table 5).

Table 6, then presents the Authors' Keywords (DE) and the Keywords associated with the document by WoS database (ID) which occur more than once. The results tell us that the most frequent author Keywords in the data are "model" "care", "technology" and "system". 
Table 3. Most Productive Authors

\begin{tabular}{llll|}
\multicolumn{1}{c}{ Authors } & Articles & \multicolumn{1}{c}{ Authors-Frac } & Articles Fractionalized \\
MATHIASSEN L & 4 & BURCHERT H & 2.0000 \\
STANDING C & 4 & ESSEN A & 1.5000 \\
CHO S & 3 & HASSAN NM & 1.5000 \\
HASSAN NM & 3 & MAON SN & 1.5000 \\
MAON SN & 3 & MATHIASSEN L & 1.5000 \\
SARABDEEN J & 3 & STANDING C & 1.4500 \\
AARNIO E & 2 & JANKAUSKIENE D & 1.3333 \\
BAKALA M & 2 & SARABDEEN J & 1.3333 \\
BENNANI AE & 2 & WICKRAMASINGHE N & 1.2500 \\
BURCHERT H & 2 & CHO S & 1.1667 \\
CRIPPS H & 2 & AARNIO E & 1.0000 \\
ESSEN A & 2 & AL-SOLBI AN & 1.0000 \\
FRAGIDIS G & 2 & ANNA SHILLABEER AS & 1.0000 \\
GURURAJAN R & 2 & BYGSTAD B & 1.0000 \\
HUANG W & 2 & CHAROENSIRIWATH S & 1.0000 \\
JANKAUSKIENE D & 2 & CRIPPS H & 1.0000 \\
LIF & 2 & DUCLOS V & 1.0000 \\
LI H & 2 & GAN I & 1.0000 \\
MICHALSKI M & 2 & GBADEGESHIN SA & 1.0000 \\
MIKULSKIENE B & 2 & KACHIENGA MO & 1.0000
\end{tabular}

Table 4. Top manuscripts per citations

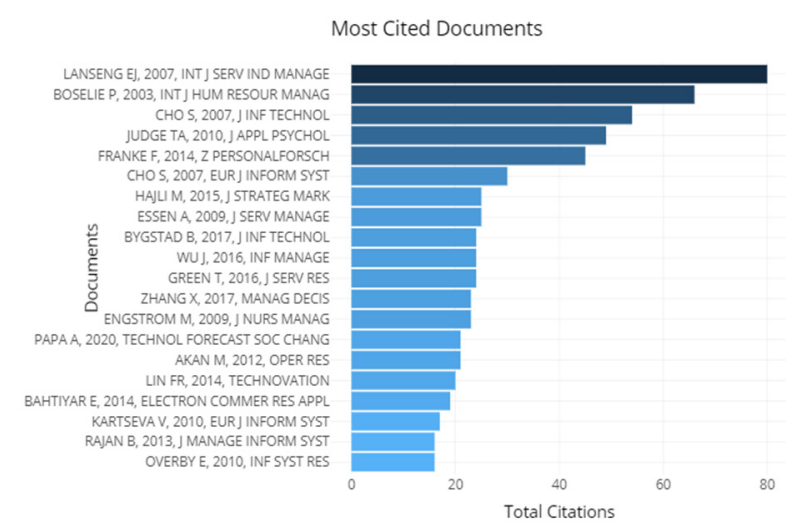

Table 5. Most Relevant Sources

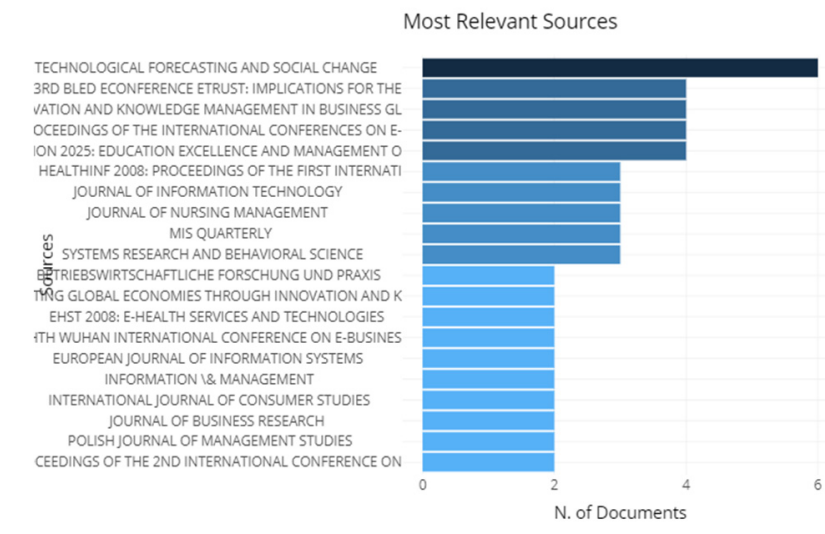


Table 6. Most Relevant Keywords
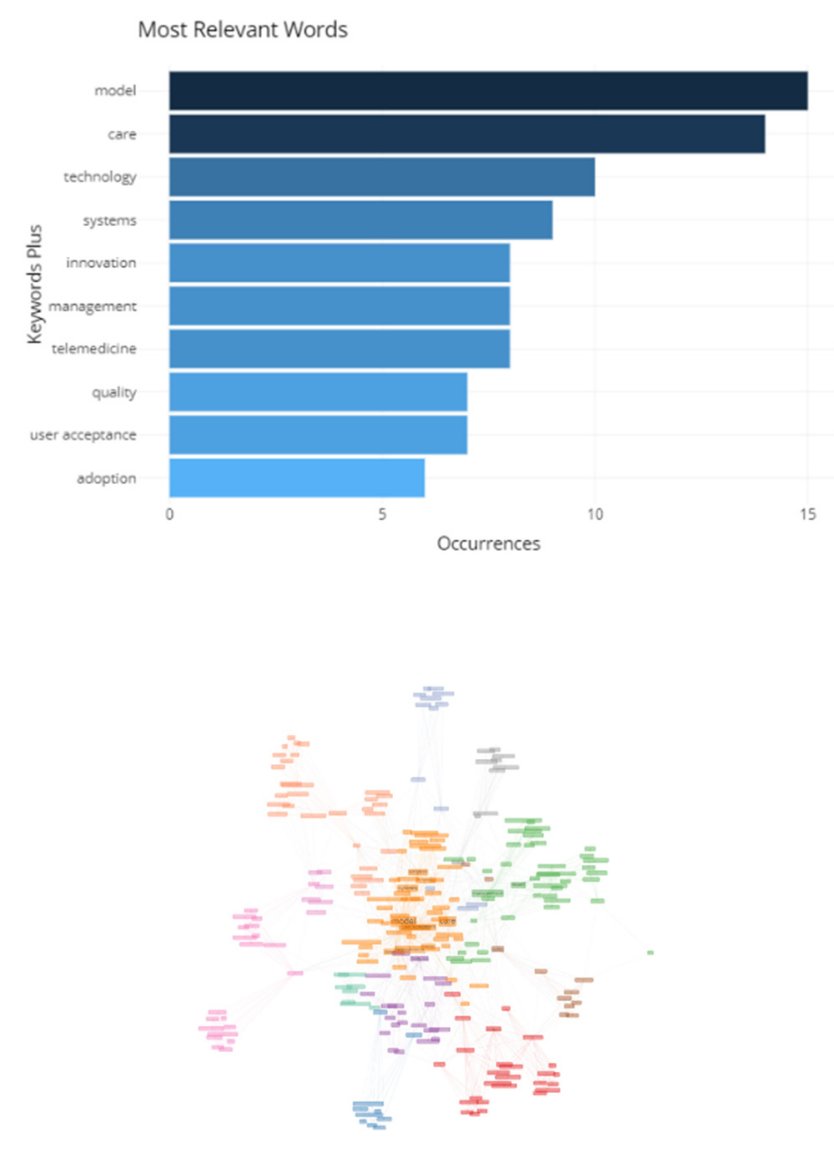

Figure 3. Dendrogram of the documents

Table 7. Cluster results

\begin{tabular}{|c|c|c|c|}
\hline Occurrences & Words & Cluster & Cluster_Label \\
\hline 8 & management & 1 & management \\
\hline 5 & framework & 1 & management \\
\hline 6 & impact & 1 & management \\
\hline 6 & health-care & 2 & health-care \\
\hline 6 & information-technology & 3 & model \\
\hline 7 & user acceptance & 3 & model \\
\hline 15 & model & 3 & model \\
\hline 14 & care & 3 & model \\
\hline 8 & innovation & 3 & model \\
\hline 6 & internet & 3 & model \\
\hline 10 & technology & 3 & model \\
\hline 9 & systems & 3 & model \\
\hline 8 & telemedicine & 3 & model \\
\hline 5 & design & 3 & model \\
\hline 5 & implementation & 3 & model \\
\hline 6 & adoption & 3 & model \\
\hline 7 & quality & 4 & quality \\
\hline 6 & telehealth & 5 & telehealth \\
\hline
\end{tabular}

A useful dimension to comment the co-citation networks is a clusters analysis: we found four clusters with a transversal fifth one that is "telehealth". The clusters are: 
- Management.

- Healthcare Service.

- Information.

- Quality.

Following, the results of documents discussion, analysing most significant documents, according to previous ranking, with a special attention to 2020 production, that, due to Covid emergency, has an instant approach.

\section{Cluster 1: Management}

First Cluster is described by the word "management" that is the topic of these articles on virtual healthcare. All the authors, interesting for our literature review are focused on managerial evidence of introduction of digital systems in sanitary field. Some sub-topics are linked to specific aspect of management, Jefferies et al. (2019) extend discussion on value co-creation by examining user perspectives on institutional measures of service systems and how these affect customers' attempts to pass through service interactions. Healthcare provides the experimental context for the study focusing on a digital service knowledge built-in into customer interfaces. Another interesting example is given by Silva et al. (2019), that focus on mobile health (m-Health) and value co-creation. m-Health systems offer mobility as precious resource to interact between mobile health systems and patient problems, outstanding the significance of privacy and managing data.

Other authors of this cluster concentrate on self-monitoring and the impact on public policies (Lanseng \& Andreassen, 2007) and an inclusive access to health services. Cho et al (2007) study on the telehealth innovation and Cho and Mathiassen (2007) investigate on information-intensive nature of the healthcare industry and the potential to reduce costs and improve quality of services for an integrated health system. The studies contribute with a cost- efficacy analysis about technology in sanitary field. Wu et al. (2016) discuss on E-health synergy, integration work and hospital is bigger than the merged intensity of the differing forces.

Papa et al. (2020) in a really recent study focus on really new technology, Internet of Things and wearable devices that are important application during Covid times, stressing the concept of remote controlling, and Rajan et al (2013), some years ago, concentrate on same management remote control models on patients who live farther away from the hospital and the impact of telemedicine on the competitive balance between hospitals.

\section{Cluster 2: Healthcare Service}

The second cluster is correspondent to the concept of service, healthcare service. These documents stress the evidence about new models of service and how these models impact on citizen health. George and Bucatariu (2020), in a recent article raise this proposition in NCOVID-19 context. According to these authors telehealth has been playing an increasingly key role in the management of the NCOVID-19 crisis: the application of social distancing measures has had the result of reduced technology distance in almost every walk of life. In this paper, based primarily on the still evolving experiences of utilizing it during the Covid- 19 crisis, telehealth has finally affirmed itself as the solution for service needs.

What was just an experimentation for former authors as AlDossary, Martin-Khan, Bradford, \& Smith (2017) or George \& Salgaonkar, 2006; Mekoth, et al., (2012), in NCOVID-19 time become a strong opportunity to be a new service model.

These new views of an integrated sanitary model for health inclusion started in significant studies especially in Northern Europe. Essén (2009), in "The emergence of technology-based service systems: A case study of a telehealth project in Sweden" proposed a framework for studying the process of technology-based service system innovation from a broad perspective. The framework draws on Lévy-Strauss's concept of bricolage, which implies that individuals' "making do with resources at hand," as opposed to managerial visions, can prompt innovation. This paper is focused on user innovation that becomes a more and more interesting perspective and in ten years this new framework is now a consolidated one. Lin and Hsieh (2013) in their study on telehealth service target customers' need. Based on multiple case study findings, this research identified challenges for the new service development projects such as user needs identification. A sustainable healthcare service requires clearly identified user needs and mature technology, organization, and individual service providers.

\section{Cluster 3: Information}

Cluster 3 is a little papers group concentrated on "information" and the role of data managing for public health. Aarnio \& Raitoharju (2008) in their chapter focused on how many areas of the healthcare sector are information-rich and data-intensive. Patient-specific prescription information is often seen as incredibly important part of patient data for patients' safe treatment and therefore the availability of it should be an incredible resource of knowledge. The aim of this paper is to study healthcare professionals' perceptions of their use of sources of 
medication information and to assess it in the light of national e-Health scenarios using a Finnish primary care organization as a case study. The data are seen from professional's perspective that is an important point of view. The future e-Health solutions should be usable and ensure the correctness and completeness of the treatment information if the clinical workers are expected to use them. The valuable information provided by the patients could be also exploited more efficiently in the future as big data for studies in medical field but also in managerial one.

Another significative study was given by Grain et al. (2008) that in a conference investigate on Australia sanitary system, confronting an ageing population with complex demographics. Ensuring continued healthcare for the ageing, while providing sufficient support for the already aged population requiring assistance, is at the forefront of the national agenda. Information is an important answer to this context and collection of data is an important output of that condition.

\section{Cluster 4: Quality}

At the end of this analysis a little cluster put on evidence the concept of quality in virtual healthcare for integrated services. Wickramasinghe et al. (2005) in "Assessing E-Health" focus on the fact that while healthcare is the main service industry on the world, it has yet to realize the full capacity of the e-business transformation in the form of e-health. This is due to many reasons, including the fact that the healthcare industry is faced with many complex challenges in trying to deliver cost-effective, high-value, accessible healthcare and has traditionally been gradual to adopt new business techniques and technologies. Given that e-health to a great degree is a macro-level interest that has far reaching micro-level consequences, this chapter first develops a quality framework to assess a country's readiness to supporting e-health (i.e. the application of e-commerce to healthcare) and from this, an e-health preparedness net to facilitate the estimation of any e-health initiative.

Another focus on quality service is given by Roberts and Alsop (2003) that investigate about access, choice, communication, and service providing. It implies that one of the prime functions of e-healthcare is to deliver a range of effective and efficient information services based on specific needs of different user groups such as health institutions, health professionals and citizens.

\section{Conclusion and Future Research}

This review is useful to find research gap in the considerate topic and could help to determine the effectiveness of virtual healthcare and telemedicine technologies in patient's needs. Since a twenty-year application, an emergent situation, due to pandemic problems, test, and stress sanitary system with e-health answers, completely changing managing prospective and updating scholars contributes. The authors aimed to systematically review the effectiveness of telehealth on patient's needs and healthcare services.

Telemedicine is the provision of health services when distance is a critical factor, so it is necessary for operators to use information and communication technologies in order to exchange data useful for diagnosis and treatment of diseases. Telemedicine guarantees continuous information to healthcare providers and supports research and evaluation of care. An important aspect is that telemedicine allows a reduction of both the phenomenon of "health migration" and the costs that a patient must bear and allowing these patients a simpler self-management and giving them the opportunity to be more autonomous. The NCOVID-19 crisis threw telehealth into a situation completely new and put experimentations in a new stressed application but really significant for managerial views and paradigms. A new research gap is now occurred in literature and a significant new trend development could be part of close future research. We are aware that pandemic status will be at the same time an acceleration but also a new paradigm is coming in healthcare. All these experiences must be analysed and studied, moving from an operative level to a theoretical one, so a further study is our purpose.

\section{References}

Aarnio, E., \& Raitoharju, R. (2008). The Use of Data Sources of Medication Information - a Finnish Primary Care Organization in the Light of National e-Health Scenarios. In Towards Sustainable Society on Ubiquitous Networks (pp. 209-219). https://doi.org/10.1007/978-0-387-85691-9_18

AlDossary, S., Martin-Khan, M. G., Bradford, N. K., \& Smith, A. C. (2017). A systematic review of the methodologies used to evaluate telemedicine service initiatives in hospital facilities. International Journal of Medical Informatics, 97, 171-194. https://doi.org/10.1016/j.ijmedinf.2016.10.012n

Aria, M., \& Cuccurullo, C. (2017). Bibliometrix: An R-tool for comprehensive science mapping analysis. Journal of Informetrics, 11(4), 959-975 https://doi.org/10.1016/j.joi.2017.08.007 
Briner, R. B., \& Denyer, D. (2012). Systematic review and evidence synthesis as a practice and scholarship tool. In Handbook of evidence-based management: Companies, classrooms and research (pp. 112-129). https://doi.org/10.1093/oxfordhb/9780199763986.013.0007

Broadus, R. (1987). Toward a definition of bibliometrics Scientometrics. https://doi.org/10.1007/BF02016680

Callon, M., Courtial, J. P., Turner, W. A., \& Bauin, S. (1983). From translations to problematic networks: An introduction to co word analysis. Social Science Information, 22(2), 191-235. https://doi.org/10.1177/053901883022002003

Cho, S., Mathiassen, L., \& Robey, D. (2007). Dialectics of resilience: a multi-level analysis of a telehealth innovation. Journal of Information Technology, 22(1), 24-35 https://doi.org/10.1057/palgrave.jit.2000088

Cobianchi, L., \& Pugliese, L. (2020). Planning the Full Recovery Phase. An Antifragile Perspective on -surgery After COVID-19. Surgical Perspective, 272(6), 296-299. https://doi.org/10.1097/SLA.0000000000004489

Crane, D. (1972). Invisible colleges: Diffusion of knowledge in scientific communities. Chicago: University of Chicago Press.

Diodato, V. (1994). Dictionary of bibliometrics. Binghamton, NY: Haworth

Elton, J., \& O'Riordan, A. (2016). Healthcare disrupted: Next generation business models and strategies. John Wiley \& Sons.

Essén, A. (2009). The emergence of technology-based service systems. Journal of Service Management. https://doi.org/10.1108/09564230910936878

George, B. P., \& Salgaonkar, P. B. (2006). Inter-Relationship Among the Extent of Past Consultations, Recommendation, Satisfaction, and Loyalty in Patient-Doctor Relationship: An Empirical Study. Journal of Global Academy of Marketing Science, 16(3), 17-37. https://doi.org/10.1080/12297119.2006.9707369

George, B., \& Bucatariu, L. (2020). The 'Coming of Age' of Telehealth, with NCOVID-19 in Context. https://doi.org/10.20944/preprints202005.0282.v1

Grain, H., Robinson, K., Torney, B., Fraunholz, B., \& Unnithan, C. (2008). Healthcare in continuum for an ageing population. In Healthinf 2008: Proceedings of the first International Conference on Health Informatics. INSTICC, Madeira, Portugal, 266-273.

Izzo, F., \& Camminatiello, I. (2020). Gaming for Healthcare: A bibliometric analysis in Business and Management. International Business Research, 13(12), 27-41. https://doi.org/10.5539/ibr.v13n12p27

Jefferies, J. G., Bishop, S., \& Hibbert, S. (2019). Customer boundary work to navigate institutional arrangements around service interactions: Exploring the case of telehealth. Journal of Business Research, 105, 420-433 https://doi.org/10.1016/j.jbusres.2019.03.052

Lebart, L., Morineau, A., \& Warwick, K. M. (1984). Multivariate descriptive statistical analysis (correspondence analysis and related techniques for large matrices). Chichester: Wiley.

Lin, F. R., \& Hsieh, P. S. (2014). Analyzing the sustainability of a newly developed service: An activity theory perspective. Technovation, 34(2), 113-125 https://doi.org/10.1016/j.technovation.2013.08.004

Mekoth, N., George, B. P., Dalvi, V., Rajanala, N., \& Nizomadinov, K. (2012). Service quality in the public sector hospitals: a study in India. Hospital topics, 90(1), 16-22. https://doi.org/10.1080/00185868.2012.661322

Papa, A., Mital, M., Pisano, P., \& Del Giudice, M. (2020). E-health and wellbeing monitoring using smart healthcare devices: An empirical investigation. Technological Forecasting and Social Change, 153, 119-226. https://doi.org/10.1016/j.techfore.2018.02.018

Pritchard, A. (1969). Statistical bibliography or bibliometrics. Journal of Documentation, 25, 348.

Rajan, B., Seidmann, A., \& Dorsey, E. R. (2013). The competitive business impact of using telemedicine for the treatment of patients with chronic conditions. Journal of Management Information Systems, 30(2), 127-158 https://doi.org/10.2753/MIS0742-1222300205

Roberts, B., \& Alsop, G. (2003). Public Services: E-Governance and E-Health-What are we really talking about? 'A Cure All for all Ills? In Towards the Knowledge Society, 513-523. https://doi.org/10.1007/978-0-387-35617-4_33

Rousseau, D. M. (2012). The Oxford handbook of evidence-based management. Oxford University. https://doi.org/10.1093/oxfordhb/9780199763986.001.0001 
Rousseeuw, P. J. (1987). Silhouettes: A Graphical Aid to the Interpretation and Validation of Cluster Analysis. Journal of Computational and Applied Mathematics, 20, 53-65. https://doi.org/10.1016/03770427(87)901257

Silva, B. M., Rodrigues, J. J., Canelo, F., Lopes, I. M., \& Lloret, J. (2019). Towards a cooperative security system for mobile-health applications. Electronic Commerce Research, 19(3), 629-654. https://doi.org/10.1007/s10660-018-9296-9

Sousa, M. J., Pesqueira A. M, Lemos C., Sousa M., \& Rocha A. (2019). Journal of Medical Systems, 43(290), 2-10. https://doi.org/10.1007/s10916-019-1419-x

Verbeek, A., Debackere, K., Luwel, M., \& Zimmermann, E. (2002). Measuring progress and evolution in science and technology I: The multiple uses of bibliometric indicators. International Journal of management reviews, 4(2), 179-211. https://doi.org/10.1111/1468 2370.00083.

Vitacca, M., Mazzù, M., \& Scalvini, S. (2009). Socio-technical and organizational challenges to wider e-Health implementation. Chronic respiratory disease, 6(2), 91-97. https://doi.org/10.1177/1479972309102805

Waltman, L. (2016). A review of the literature on citation impact indicators. Journal of Informetrics, 10(2), 365-391. https://doi.org/10.1016/j.joi.2016.02.007

Wickramasinghe, N., Geisler, E., \& Schaffer, J. (2006). Assessing e-health. E-health systems diffusion and use: The innovation, the user and the use it model. https://doi.org/10.4018/978-1-59140-423-1.ch017

\section{Copyrights}

Copyright for this article is retained by the author(s), with first publication rights granted to the journal.

This is an open-access article distributed under the terms and conditions of the Creative Commons Attribution license (http://creativecommons.org/licenses/by/4.0/). 